TENDENCIAS

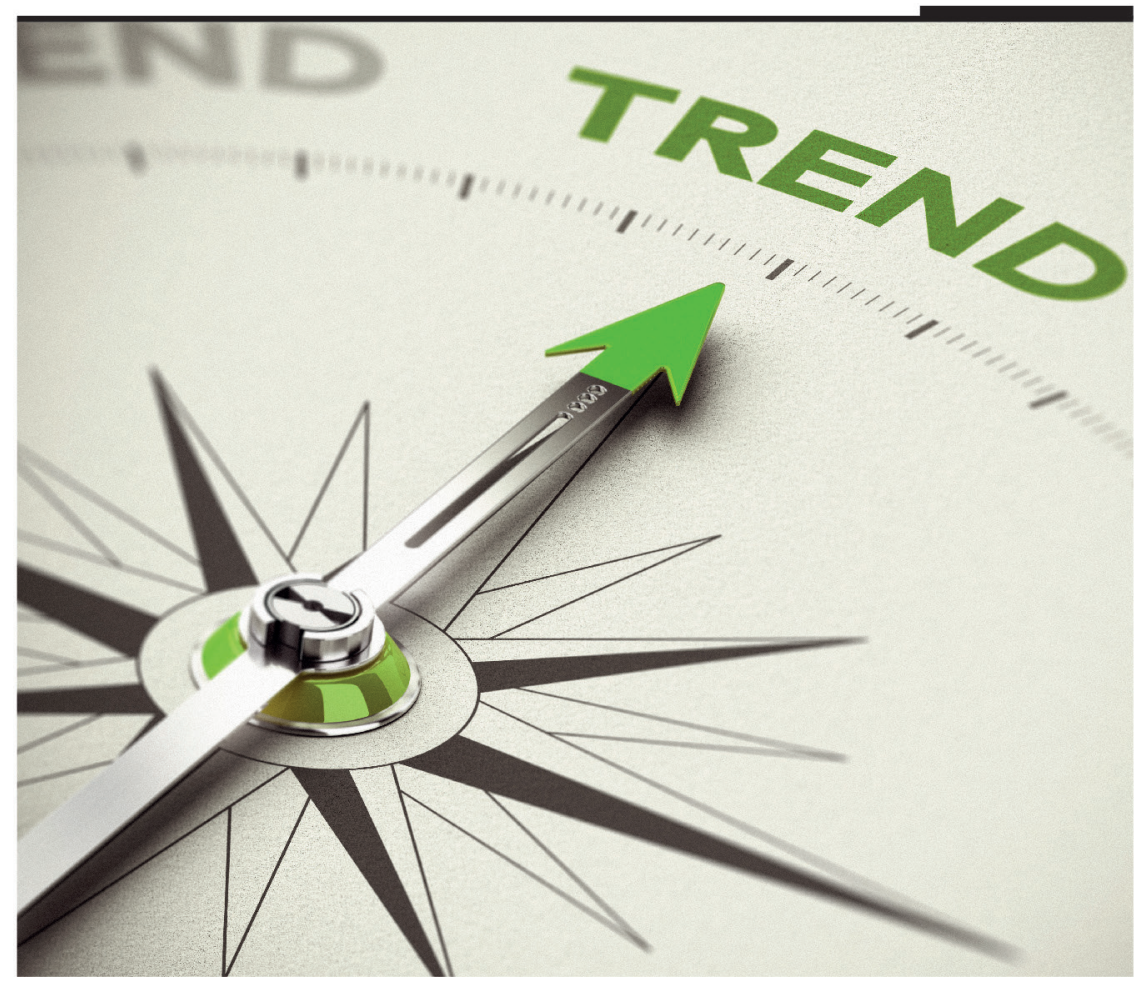





\title{
LA ADAPTACIÓN DEL PERIODISMO ESPECIALIZADO EN SALUD AL ENTORNO DIGITAL. ANÁLISIS DE LAS PRÁCTICAS PERIODÍSTICAS EN CIBERMEDIOS MEXICANOS
}

\author{
JosÉ ISRAEL RIVERA TERRAZAS' \\ Universidad Panamericana, México \\ israelxy@hotmail.com
}

Recibido: 28/3/2019 / Aceptado: 16/5/2019

doi: $10.26439 /$ contratexto2019.n032.4623

\begin{abstract}
Resumen. Actualmente, es común encontrarse no solo con secciones de periodismo en salud adaptadas a su soporte digital, sino que también es posible ver medios especializados creados para generar contenidos exclusivos para internet, así como periodistas, piezas clave en el proceso de construcción y contextualización de la información sobre salud, mejor acoplados a internet para cumplir con las expectativas y demandas de usuarios cada vez más dependientes de las nuevas tecnologías. A través de entrevistas en profundidad a diez periodistas de cuatro cibermedios mexicanos, este artículo analiza cómo se adapta el periodismo especializado en salud a la interactividad, hipertextualidad, multimedialidad e inmediatez del ciberperiodismo para llevar a cabo prácticas periodísticas que permiten la construcción de contenidos informativos. Desvela que la falta de recursos humanos en los cibermedios y la carencia de habilidades relacionadas con el entorno digital representan los principales obstáculos para la adaptación del periodismo en salud.
\end{abstract}

Palabras clave: ciberperiodismo / periodismo digital / periodismo en salud / prácticas periodísticas / comunicación

1 Doctor en Ciencias Políticas y Sociales por la Universidad Nacional Autónoma de México. http://orcid. org/0000-0002-1566-3320 


\title{
ADAPTATION OF HEALTH JOURNALISM TO DIGITAL ENVIRONMENT. AN ANALYSIS OF JOURNALISTIC PRACTICES IN MEXICAN CYBERMEDIA
}

\begin{abstract}
Currently, it is common to find not only sections of health journalism adapted to their digital media but also specialized media created to generate exclusive content for the Internet, as well as journalists, who are the key players in the process of construction and contextualization of health information, and are better adapted to the Internet to meet the expectations and demands of users who increasingly depend on new technologies. Using in-depth interviews conducted with ten journalists from four Mexican cybermedia, this article analyzes how health journalism adapts to the interactivity, hypertextuality, multimedia and immediacy of cyberjournalism to carry out journalistic practices that allow the construction of informative content. Moreover, it reveals that the shortage of journalists in cybermedia and the lack of skills related to the digital environment represent the main obstacles for the adaptation of health journalism.
\end{abstract}

Keywords: cyberjournalism / digital journalism / health journalism / journalistic practices / communication.

\section{A ADAPTAÇÃO AO MEIO DIGITAL DO JORNALISMO ESPECIALIZADO EM SAÚDE. ANÁLISE DAS PRÁTICAS JORNALIISTICAS NA CIBERMÍDIA MEXICANA}

Resumo. Atualmente, é comum encontrar não apenas seções de jornalismo em saúde adaptadas ao seu suporte digital, mas também é possível observar mídias especializadas criadas para gerar conteúdo exclusivo para a internet, bem como jornalistas, atores chave no processo de construção e contextualização de informações de saúde, melhor acoplados à internet para atender às expectativas e demandas de usuários cada vez mais dependentes de novas tecnologias. Através de entrevistas aprofundadas com dez jornalistas de quatro cibermídias mexicanas, este artigo analisa como o jornalismo especializado em saúde se adapta à interatividade, hipertextualidade, multimídia e imediação do ciberjornalismo para realizar práticas jornalísticas que permitem a construção de conteúdos informativos. E revela que a falta de recursos humanos na cibermídia e a falta de habilidades relacionadas ao meio digital representam os principais obstáculos para a adaptação do jornalismo em saúde.

Palavras-chave: ciberjornalismo / jornalismo digital / jornalismo em saúde / práticas jornalísticas / comunicação 


\section{INTRODUCCIÓN}

Desde mediados de la década de los noventa del siglo pasado, internet se ha convertido en una plataforma importante para la difusión y consulta de información relacionada con la salud.

Cada vez con mayor frecuencia, las personas acuden a sus computadoras o dispositivos móviles para teclear en los diferentes buscadores a su disposición los nombres de enfermedades, de medicamentos y hasta los signos y síntomas que manifiestan ellos mismos, o bien, algún familiar o conocido, con la esperanza de encontrar respuestas que les permitan entender mejor sus padecimientos y hallar tratamientos o profesionales de la salud que les ayuden a controlar sus afecciones y mejorar su calidad de vida. Y es que la información sobre lo que nos enferma, lo que nos provoca la muerte o lo que nos cura nos importa y nos motiva a querer saber más.

De ahí, que actualmente sea común escuchar en las conversaciones de la gente, ante cualquier inquietud relacionada con la salud propia o ajena, frases como: "¡Mira en internet!” o “iPregúntale al doctor Google!”, debido a la penetración que hoy tiene esta práctica en la población que cuenta con acceso a internet.

Es así que los sitios web relacionados con la salud -no solo los que pertenecen a empresas periodísticas, sino también los creados por instituciones de salud, laboratorios farmacéuticos y otras empresas cuya producción está relacionada con el campo de la salud, universidades y centros de investigación y sociedades de pacientes- han aumentado de forma exponencial y se encuentran entre los más visitados por los usuarios de internet. Entre otras razones, por ser de acceso libre, por su bajo costo en cuanto a inversión y mantenimiento, por la rápida transmisión de la información y por no necesitar la intervención de un mediador, es decir, de un medio de comunicación, para su difusión (Roqué, 2007).

El fenómeno, además, se acompaña de un interés público sobre temas de salud que va en aumento (Shah, 2011). El estudio 24 percent of mexican Internet users visited health sites in February 2013, realizado por ComScore (2013), indica que en México 5,8 millones de usuarios de internet, que equivale al veinticuatro por ciento del total de la población que cuenta con conexión en su hogar, visitó en febrero del 2013 algún sitio web relacionado con la salud.

Según este artículo, México ocupó el segundo lugar en cuanto al número de cibernautas que visitaron alguno de estos sitios web en Latinoamérica en la fecha mencionada, solo por debajo de Brasil que registró 23,2 millones de visitas, lo que representa el 37,7 por

2 En México se carece de información sobre este tema. El estudio de ComScore es de los pocos que ofrece datos al respecto. 
ciento de la población con conexión a internet en ese país. Mientras que Argentina se ubicó en el tercer lugar, con 2,7 millones de visitas y Colombia en cuarto lugar, con 2,2 millones de visitas.

Así, bajo este contexto es como se ha dado la migración del periodismo especializado en salud al ciberespacio. El número creciente de cibernautas, "inmediatamente convertidos en consumidores de información periodística gratuita en Internet" (Salaverría, 2016, p. XXVII), propició que el periodismo volteara a ver con curiosidad e incertidumbre, primero, y con interés periodístico y económico, después, este nuevo medio.

Lo que es un hecho es que ahora es más común encontrarse no solo con secciones y suplementos de salud adaptados a su soporte digital, sino también es posible ver medios especializados en salud creados para generar contenidos exclusivos para internet y periodistas de salud, quienes son piezas clave en el proceso de construcción y contextualización de la información sobre salud, mejor acoplados al medio digital para cumplir con las expectativas y demandas de su público cada vez más dependiente de las nuevas tecnologías.

\section{METODOLOGÍA}

Para la realización de este estudio se consultó a periodistas de salud de cuatro cibermedios mexicanos con el objetivo de identificar cómo se adaptan las prácticas periodísticas a las características de interactividad, hipertextualidad, multimedialidad e inmediatez del ciberperiodismo para construir el discurso informativo.

A través de entrevistas en profundidad, los periodistas de salud proporcionaron información detallada que permite identificar las innovaciones específicas realizadas en la construcción del discurso, tanto en lo personal como grupal (en el cibermedio); además de que surgieron datos con los que fue posible observar las similitudes y diferencias entre los distintos productores de contenidos periodísticos sobre salud.

Las entrevistas fueron semiestructuradas. Para ello se elaboró un cuestionario flexible y con preguntas abiertas, que, aunque mantenía un orden temático, permitió modificar la secuencia o el ángulo de las preguntas de acuerdo con las características de cada entrevista. Lo que se buscó fue indagar en dos categorías principalmente:

1) Información profesional. Para conocer su formación académica y su experiencia periodística en el campo de la salud.

2) Adaptación a las características de internet. Para entender cómo los cibermedios y los periodistas se adaptan a la interactividad, hipertextualidad, multimedialidad e inmediatez en su ejercicio diario. 
Las entrevistas en profundidad se realizaron entre diciembre del 2015 y marzo del 2016. En una primera etapa se entrevistó a editores y coordinadores editoriales de cuatro cibermedios: reforma.com (sección Vida), sinembargo.com (sección Salud y Bienestar), salud180.com y sumedico.com, y en una segunda etapa, siguiendo el muestreo de bola de nieve, que es una técnica de muestreo no probabilístico que permite la identificación de sujetos potenciales a partir de la designación de los primeros sujetos contactados, se consultó a reporteros, redactores y coeditores gracias al apoyo de los editores y coordinadores editoriales, quienes permitieron la identificación y facilitaron el contacto con otros integrantes de su cibermedio.

El trabajo de campo concluyó tras la realización de diez entrevistas, a ocho mujeres y dos hombres, que tuvieron una duración de entre una hora y media y dos horas. Solo dos entrevistas tuvieron lugar en la sala de redacción de los cibermedios, las otras ocho se realizaron en sitios propuestos por los propios entrevistados, como cafeterías y restaurantes. Su participación fue voluntaria, por lo que no se ofrecieron incentivos para su colaboración, y de común acuerdo con los periodistas se determinó al principio y final de las entrevistas que sus respuestas permanecerían en el anonimato y que toda la información sobre su identidad o de relación con su cibermedio se retiraría del desarrollo y resultados de este trabajo.

\section{RESULTADOS}

\section{El perfil profesional de los periodistas de salud}

El primer aspecto por destacar es la formación académica de los sujetos entrevistados. Los diez periodistas manifestaron haber estudiado la Licenciatura en Ciencias de la Comunicación o en Periodismo; seis de ellos cuentan con el título profesional de licenciatura y de ellos solo uno tiene estudios de posgrado: una maestría en Comunicación Aplicada y Planeación de Medios en la Universidad Anáhuac y un máster en Periodismo Digital en la Universidad Complutense de Madrid.

Ninguno de ellos proviene de otra disciplina académica, como suele ocurrir sobre todo cuando se cubren ciertas áreas especializadas, como política, finanzas, cultura, deportes, moda o gastronomía, en donde se pueden contar abogados, economistas, sociólogos, historiadores, deportistas, artistas (escritores, músicos, pintores), expertos en moda, cocineros y, en el caso que nos ocupa, profesionales de la salud (médicos, enfermeros, farmacéuticos, terapeutas o psicólogos, entre otros). Aquí todos son periodistas de carrera, ninguno de los entrevistados se especializó en las áreas de la salud o la ciencia durante su formación académica. 
Sobre la capacitación en el campo de la salud, únicamente cuatro periodistas manifestaron que toman o tomaron cursos, gratuitos o pagados, de actualización en temas de salud o en primeros auxilios que ofrecen instituciones de salud, compañías farmacéuticas o universidades.

En este punto existen opiniones muy variadas. Mientras algunos consideran esencial la capacitación en el área para lograr un mejor desempeño profesional y mejores contenidos, otros señalan que solo basta con la experiencia que brinda la cobertura diaria para hacer un buen trabajo.

En el primer grupo destacan declaraciones como la siguiente:

Sí se necesita capacitarse en el periodismo en salud, así como lo hacen en otras áreas del periodismo, por ejemplo, el periodismo de finanzas o el de ciencia, porque manejas información que además de ser muy delicada es muy especializada. Cuando haces periodismo en salud, no puedes equivocarte con los datos, porque, aunque no lo parezca, hay mucha gente que toma esa información que se publica al pie de la letra y si te equivocas en algo puedes generar un problema. Por eso creo que sí hace falta profesionalización. Pero además tienes que capacitarte y aprender terminología médica, porque a veces cuando llegas con un experto no siempre te va a explicar cada cinco minutos qué significa algo, porque ocurre con mucha frecuencia que escuchas términos de la jerga médica que no tienes por qué dominar, porque no eres médico, pero que debes entender por lo menos y para eso se necesita tener un poquito de bagaje para que exista un entendimiento entre el periodista y el especialista. (Coordinadora editorial, comunicación personal n. ${ }^{\circ} 6$, febrero del 2016)

Mientras que, en el segundo grupo, algunos periodistas concuerdan con la siguiente opinión:

Sí se necesita la capacitación, pero no de entrada. Yo partí de cero, pero conforme estás en la fuente te vas curtiendo y de pronto llega un momento en el que adquieres conocimientos que te permiten saber de qué están hablando los expertos o para saber si el tema es interesante o no. Conocer sobre la fuente sí es una ventaja, pero no creo que para trabajar en el periodismo en salud se necesite un conocimiento tan especializado como en otras fuentes, como por ejemplo en economía, porque ahí no puedes entrar de cero. No estaría de más tener una capacitación específica en el área, pero no creo que sea necesario. Además, para muchos de los trabajos que hacemos contactamos a especialistas para que expliquen los temas. Claro, no le decimos al experto: "Me explica a mí", sino que le pedimos que hable de una manera sencilla que permita que los lectores entiendan de lo que habla. (Coordinadora editorial, comunicación personal n. ${ }^{\circ}$ 5, febrero del 2016)

De acuerdo con la información proporcionada, tanto para los periodistas como para los cibermedios tiene más importancia la capacitación en periodismo y marketing digital que en periodismo en salud, ya que, en términos pragmáticos, son áreas que les resultan 
más útiles para el desarrollo de sus rutinas. Los entrevistados señalaron que en tres de los cibermedios seleccionados los capacitan constantemente en temas relacionados con marketing y posicionamiento en internet. Lo común es que los medios contraten a otras empresas que ofrecen cursos sobre analítica web y redacción SEO (Search Engine Optimization), como explica una redactora: "Acá nos capacitan a todos para SEO. Aquí nos dan varios cursos que imparten empresas que contratan para esto" (redactora, comunicación personal n. ${ }^{\circ} 10$, marzo del 2016).

$Y$ en su caso, que es el único entre los cuatro cibermedios analizados, los instruyen en el manejo de CMS (Content Managment System) o Sistema de Gestión de Contenidos y en producción y edición de recursos audiovisuales, capacitación que ofrecen empresas externas, o bien, otros miembros del equipo que ya han tomado cursos en estas áreas: “También nos dan talleres de redacción para periodismo digital, estos los dan nuestros jefes, quienes vienen de prensa escrita, pero que se han ido capacitando en ciberperiodismo" (redactora, comunicación personal n. ${ }^{\circ} 10$, marzo del 2016).

En los otros cibermedios, los periodistas han tenido que aprender "sobre la marcha", de manera autodidacta, así como refiere una editora:

Mi formación en el periodismo digital ha sido a través de la práctica diaria, porque todos llegamos y pensamos que el periodismo digital es como hacer periodismo tradicional, y no es lo mismo, pero lo vas adaptando, te vas dando cuenta de que tienes otras necesidades, que tienes que utilizar tal vez hasta otro tipo de lenguaje para hablarle al lector. No he tomado cursos como tales, pero sí asesorías en SEO. De programación y diseño he aprendido sola, por ejemplo, tuve que aprender sola a manejar un CMS, para poder realizar mi trabajo diario, porque no podía estar dependiendo todo el tiempo de un desarrollador. (Editora, comunicación personal n. ${ }^{\circ}$, diciembre del 2015)

Es decir, la especialización en periodismo en salud se deja en segundo plano para enfocar sus esfuerzos a adaptarse lo mejor posible a las particularidades de internet y a las nuevas dinámicas en los cibermedios, las cuales han traído, entre otras cosas, la multiplicación de las tareas y responsabilidades de los periodistas de salud. Así lo explica una reportera:

Prácticamente somos unos multiusos, además de hacer notas, manejamos redes sociales, hacemos y editamos videos, hacemos el diseño de los contenidos. Cuando terminé la carrera, yo solo sabía medio escribir. Tuve que aprender paquetería de Photoshop e Illustrator. Tuve que aprender a manejar redes sociales y a hacer infografías, que es una tarea de diseño. Yo lo aprendí por mi cuenta, a puro manual, soy autodidacta. Aquí [en su cibermedio] para lo único que se nos prepara constantemente es para el SEO cada seis meses nos dan un taller de SEO, porque la estrategia cambia constantemente. (Coeditora web, comunicación personal n. ${ }^{\circ} 2$, diciembre del 2015) 
Al respecto, en otros países algunas organizaciones como la Association of Health Care Journalists, en Estados Unidos, se ha preocupado por la falta de preparación de los periodistas de salud, de ahí que sugiera un código de ética en el que incluye un listado de cinco metas generales, y para alcanzarlas la asociación solicita el apoyo de periodistas, medios, universidades, instituciones de salud y empresas. Estas metas son: 1) capacitar a los periodistas en temas relacionados con medicina, cuidado de la salud, economía, política y otros temas importantes en el área; 2) promover y mejorar el apoyo al periodismo en salud; 3 ) tender puentes para garantizar la colaboración entre profesionales de la salud y periodistas; 4) recompensar la excelencia y promover mejores trabajos en el campo; y 5) abogar por el derecho de los periodistas a la información (Schwitzer, como se citó en Holton, 2013).

Entre los periodistas mexicanos consultados, a pesar de que están conscientes de la importancia de la capacitación continua en el campo de la salud para mejorar su desempeño y ofrecer mejores contenidos, no suelen hacerlo. Según refieren, esto se debe en mayor medida a que no cuentan con el tiempo para hacerlo debido a su horario prolongado de trabajo y a sus múltiples tareas diarias. Además de que, como se indicó anteriormente, algunos de ellos no lo consideran necesario.

\section{Experiencia previa al periodismo en salud}

Sobre su experiencia periodística previa al campo de la salud, todos los entrevistados señalaron que estuvieron en otras áreas periodísticas, como política, cultura, ciencia, espectáculos y suplementos especiales.

Solo uno de ellos manifestó que desde que empezó su carrera periodística tenía interés por cubrir el campo de la salud, el resto llegó ahí porque representaba una oportunidad de empleo o de crecimiento laboral dentro de la empresa. Estos son algunos de los comentarios al respecto:

Un día me di cuenta de que estaba aburrida de mi anterior trabajo, sentí que ya me había enseñado todo lo que me tenía que enseñar y quería aprender lo que era el periodismo digital, que se supone que es el nuevo periodismo, me puse a buscar y llegué aquí, pasé todos los filtros y entré. No tenía experiencia previa en salud. Decidí entrar porque tenía varios conocidos que son médicos y parientes que trabajan en el área médica y se me hizo interesante ver de qué se trataba. Pero yo no quiero especializarme en salud, yo quisiera irme a cultura, si tuviera la oportunidad de especializarme sería en periodismo cultural. (Coeditora web, comunicación personal n. ${ }^{\circ} 2$, diciembre del 2015)

Yo empecé a ejercer como periodista en la sección de cultura. Ahí empecé como reportera hace veintitrés años y luego de un tiempo me salí. Estuve como tres años fuera y luego regresé como coeditora de cultura en la versión digital. A salud llegué como parte de una evolución natural dentro del medio. Un día la editora de 
cultura, quien también tenía bajo su supervisión la sección de salud, se fue y los directivos del medio me ofrecieron quedarme como editora de esa sección, así fue como di el salto a salud. (Coordinadora editorial, comunicación personal $n .^{\circ} 6$, febrero del 2016)

Este ha sido mi único trabajo y entré porque un día me habló una amiga y me preguntó que si quería trabajar en el medio y yo le dije que sí. Empecé como redactora, con toda la información en tiempo real que llega al medio. Después me moví a un suplemento y luego cuando se abrió la sección de salud me fui para allá como editora y reportera. (Coordinadora editorial, comunicación personal n. ${ }^{\circ} 5$, febrero del 2016)

En cuanto a la experiencia profesional en el periodismo en salud, al momento de realizar las entrevistas (entre diciembre del 2015 y marzo del 2016), la mitad de los entrevistados indicó que tenía más de cinco años trabajando en esta área. El periodista con mayor experiencia dijo que tenía veintidós años de manera ininterrumpida cubriendo temas de salud, aunque a la par también se ha dedicado al periodismo en ciencia y política. Y el que menos tiempo lleva dijo que tenía un año como periodista de la fuente.

Solo una periodista indicó que no tenía experiencia en el periodismo tradicional. Al momento de la entrevista dijo que tenía veintiséis años y mencionó que su primer y único trabajo ha sido en un cibermedio. El resto ha trabajado para periódicos, revistas o radio.

Un dato por resaltar es el predominio del sexo femenino entre los periodistas que trabajan en el ciberperiodismo especializado en salud. Durante el desarrollo de la investigación se encontró que el setenta por ciento de los puestos que integran la estructura organizativa de los cibermedios analizados está ocupado por mujeres.

Este hallazgo coincide con datos presentados en el estudio Reuters Institute Digital News Report 2016 (Levy, D., Newman, N., Fletcher, R. y Nielsen, R., 2016). De acuerdo con este reporte, para el cual se consultó a periodistas de veintiséis países, dos de ellos del continente americano (Estados Unidos y Brasil), entre las mujeres periodistas la salud y la educación comparten el segundo lugar entre los temas que más les interesa cubrir, solo por debajo de las noticias locales. Mientras que en los hombres los temas de salud ocupan el séptimo lugar, los tres temas de mayor interés para ellos son noticias locales, ciencia y tecnología e internacional, en ese orden. Asimismo, el 59 por ciento de las mujeres consultadas dijo que tenía interés en las noticias de salud, en cambio, solo el 46 por ciento de los hombres mostró su interés en este tema.

\section{Las rutinas periodísticas en el ciberperiodismo en salud}

Dentro de las prácticas para la construcción del discurso informativo en el ciberperiodismo en salud, las rutinas periodísticas de acopio, selección y tratamiento de la información son una parte fundamental en dicho proceso. 
Shoemaker y Reese definen las rutinas periodísticas como "las actividades estandarizadas, rutinarias y repetitivas que realizan los trabajadores de los medios para hacer su trabajo" (1996, p. 100).

Para los periodistas entrevistados, internet, el correo electrónico y las redes sociodigitales se han convertido en herramientas primordiales para buscar y reunir información. Los utilizan como apoyo para la construcción de su agenda informativa, ya sea para encontrar temas o datos que den pie a la elaboración de contenidos exclusivos para el cibermedio, o bien, para monitorear lo que otros medios han publicado, para después retomarlo y publicarlo en sus sitios web a través de la curaduría de información.

Todos los profesionales consultados realizan la misma rutina para la búsqueda y selección de información. Al llegar a la redacción de su cibermedio, o incluso desde sus casas, monitorean en internet los contenidos de otras empresas de comunicación, sobre todo medios extranjeros, principalmente de España, Estados Unidos e Inglaterra, y también los sitios web y las redes sociodigitales de instituciones de salud y de revistas científicas especializadas en salud.

Entre los medios digitales extranjeros que más consultan los periodistas entrevistados, según ellos mismo refirieron, están: de España, El País, El Mundo y El Español; de Estados Unidos, The New York Times, The Washington Post, The Atlantic, The Huffington Post y CNN; y de Inglaterra, The Guardian y BBC. Un número de medios muy superior si se le compara con los medios nacionales que suelen consultar para encontrar inspiración para desarrollar contenidos propios y gestionar información para notas de curaduría, pues entre los medios mexicanos solo se mencionó Reforma, El Universal, Sin Embargo y Animal Político, los dos últimos como únicos representantes de cibermedios nativos.

Esta preferencia por el seguimiento de cibermedios extranjeros está relacionada con la percepción de que en el extranjero se realiza un mejor periodismo en salud que en México. Distintas declaraciones dan cuenta de ello:

De lo que me he dado cuenta es de que en el extranjero hacen un mejor trabajo. Aquí en México la calidad no es buena, la verdad es que aquí tendemos a copiarnos mutuamente entre medios, hace falta más creatividad e investigación. (Coeditora web, comunicación personal . $^{\circ} 2$, diciembre del 2015)

En México hace falta más profesionalismo y más investigación. Yo suelo monitorear otros medios, de los medios internacionales reviso, como casi todos lo hacen, The New York Times y El País, y en general creo que estos dos medios hacen una buena difusión en cuanto a temas de salud. El País nos sirve mucho como referencia, porque además de que está en el mismo idioma, nos ayuda a generar ideas. (Coeditora web, comunicación personal n. 7, febrero del 2016)

Sin embargo, esta práctica común en el ciberperiodismo en salud en México como parte de sus rutinas de acopio y selección de información genera algunos vicios, el 
primero de ellos tiene que ver con que los periodistas monitorean los mismos medios, utilizan las mismas fuentes de información, copian los mismos datos y construyen contenidos con los mismos ángulos informativos, lo que provoca la ausencia de información diferenciada y original.

Otro punto importante por destacar tiene que ver con un cambio que es cada vez más común en las rutinas de acopio de información de los ciberperiodistas, y es la sustitución del trabajo en la calle, el del contacto cara a cara con las fuentes de información, por el "cibertrabajo", el que se realiza sin tener que salir nunca de la redacción, debido a que toda la información que necesitan para generar contenidos la obtienen a través de la web o del correo electrónico. De esto están conscientes algunos periodistas con más experiencia en la fuente y quienes han vivido el cambio del periodismo tradicional al ciberperiodismo, y que al respecto señalan:

Antes, los reporteros estaban mucho en la calle. Ahora no tanto, pasan más tiempo en la redacción porque las rutinas en el periodismo digital ahora son otras. Yo trato de cuidar que no se hagan flojos, les pido que se paren de sus sillas, que salgan a investigar, que hablen con la gente, porque eso es muy importante, porque de ahí salen siempre los mejores trabajos periodísticos, porque cuando salen a la calle llegan con productos distintos, con notas o con videos que ningún otro medio trae. Internet ha facilitado las cosas, pero no hay que verlo como que ya no hay necesidad de salir a las calles, sino más bien como una herramienta para el trabajo periodístico de calidad. (Directora editorial, comunicación personal n. ${ }^{\circ} 8$, febrero del 2016)

Ahora hay más gente en la oficina, hay más gente en las redacciones y mucha información se trabaja desde el escritorio. Pero esto pasa en casi todos los países, no solo en México. Los reporteros ya no salen a la calle, todo lo hacen por internet. Se ha modificado la estructura de las redacciones, ahora hay más coeditores, más redactores y menos reporteros. $Y$ con esto no quiere decir que no sea valioso el trabajo de los coeditores y redactores, muchas veces tienen mayor capacidad de comprender un fenómeno. Sin embargo, si haces todo desde la oficina, tu información termina por parecerse a la de tus competidores, no tienes una exclusiva, porque todo el mundo busca en los mismos lugares. Por eso generalmente conservan un reportero por lo menos, para que les traiga al menos una nota diferente al día, que sea la de ellos. Pero antes había cuatro reporteros en la calle y dos personas en la oficina. (Reportero, comunicación personal $n .^{\circ} 3$, enero del 2016)

Yo creo en eso de salir y ensuciarse las botas, ver a la cara a tus fuentes, y considero que eso no se debe de perder, pero la realidad es que internet hace que la celeridad te lo impida. Para qué voy a salir a la calle a entrevistar a una fuente, cuando en el mismo tiempo puedo contactar a tres fuentes y sin moverme de mi lugar. (Reportero, comunicación personal n. ${ }^{\circ}$, febrero del 2016)

Esta tendencia puede estar motivada por una lógica de negocio, según expresan los periodistas consultados, y con esto hacen referencia a que, desde la óptica empresarial, para un cibermedio un reportero en la calle resulta menos productivo que un redactor o 
un coeditor web en el escritorio si esto se basa en el número de contenidos informativos generados por uno y otro.

Por el tiempo que un reportero invierte en realizar investigación documental sobre algún acontecimiento, hacer entrevistas presenciales con profesionales de la salud y pacientes o reportar algún procedimiento médico en una institución de salud, más el tiempo empleado en los traslados del lugar de cobertura a la redacción del cibermedio, puede generar, a lo mucho, entre dos y tres notas diarias. Mientras que un solo redactor o coeditor web puede redactar entre seis y ocho notas al día sin moverse de su lugar, a partir de la curaduría de información, de búsquedas en la red, de retomar los boletines enviados a la redacción o de entrevistas online y telefónicas con los voceros de las empresas e instituciones de salud, según manifiestan los entrevistados.

\section{Adaptación a las características de internet}

La adaptación de los periodistas de salud a la interactividad, hipertextualidad, multimedialidad e inmediatez, características que el ciberperiodismo adoptó del nuevo medio, ha significado un verdadero punto de inflexión en las prácticas periodísticas que realizan en esta fuente. A continuación, se describirán y analizarán las experiencias de los entrevistados con cada una de ellas.

\section{Adaptación a la interactividad}

Aunque todos los periodistas consultados son conscientes del acortamiento de la "distancia editorial" (Oblak citada por Díaz Noci, 2006, p. 18), lo que los ha obligado a mantener una relación más cercana con sus usuarios, y pese a que aceptan que la participación de los consumidores de noticias se ha vuelto una prioridad en el ciberperiodismo en salud, el proceso de interacción aún se muestra muy limitado.

Se utiliza, más bien, como recurso de marketing y como indicador para evaluar su productividad, a través del conocimiento de los intereses, inquietudes y necesidades informativas de las personas que visitan sus sitios web.

Un par de periodistas expresan al respecto:

Antes no tenías el feedback de la gente, y cuando lo tenías, eran casos aislados y solo le llegaban al jefe. Ahora con internet tienes el comentario y la respuesta inmediata. Como periodista, en cuestión de minutos, sabes si una nota es "jaladora" o no; sabes si al usuario le gustó o se indignó, porque en el momento en el que la publicas lo sabes, te lo hacen saber. Si a los lectores no les gusta tu trabajo te lo hacen saber de inmediato. Tienes su respuesta al instante. (Editora, comunicación personal $n .^{\circ} 4$, enero del 2016)

La relación ahora es más cercana. Si algo te permiten los medios digitales es justo la retroalimentación, la comunicación de ida y vuelta. Ahora es mucho más fácil 
que se pongan en contacto contigo a través de un correo electrónico o que dejen un comentario a una nota que se subió a internet. Creo que en ese sentido hemos ganado, porque ahora los lectores están más cerca de los periodistas. Y esto nos sirve para tomar el pulso de los temas que le interesan a la gente más rápido. No es que los usuarios intervengan de manera directa, pero sí nos permite tener este pulso mucho más a la mano y en ese sentido podemos reaccionar mucho más rápido que antes. (Coordinadora editorial, comunicación personal n. 6 , febrero del 2016)

Como es posible observar en las citas anteriores, a partir de la información que obtienen de la participación de los lectores, a los periodistas les es posible saber si los temas, los ángulos informativos y el estilo de la redacción o la estructura de los contenidos son del interés o del gusto de su audiencia, es decir, si son "jaladores", como mencionó una de las entrevistadas, haciendo referencia a que son leídos y compartidos por un gran número de personas. Así como para "tomar el pulso de los temas que le interesan a la gente" de primera mano y sin esperar demasiado tiempo, y así, sobre la marcha, incluir en sus agendas informativas los temas que no tenían contemplados. Pero hasta ahí se limita la interacción.

Esto no quiere decir que no están buscando la manera de aprovechar de una mejor forma el proceso de interacción con los usuarios, ni tampoco que no estén buscando nuevas vías para engancharlos a su cibermedio, como podría ser el involucrarlos a que participen activamente en la construcción de contenidos y no simplemente a que lean, le den clic en sus enlaces o que dejen un comentario en las notas que les ofrecen; característica que autores como Fallows (como se citó en Holton, 2013), consideran una pieza clave para la subsistencia económica de un cibermedio. Simplemente, lo que se observa es que, como herederos de la tradición del periodismo impreso, la gran mayoría de los entrevistados aún está conociendo las potencialidades del medio digital, y esto no solo ocurre con la interactividad, sino también con la hipertextualidad, multimedialidad e inmediatez.

Los cibermedios y los periodistas en salud en internet en México están intentado abrir nuevos canales para la participación de sus usuarios. Ellos invitan a la gente a que dejen algún comentario dentro de sus contenidos, o mediante un "me gusta" o un tuit o retuit en sus cuentas de Facebook o Twitter. Les ofrecen la posibilidad de compartir la información que publican en su sitio web, de enviarla por correo electrónico o de imprimirla, además de motivarlos a que se suscriban a sus boletines mensuales o que participen en foros o en charlas con expertos en tiempo real.

Pero, abrirle la puerta en sus cibermedios a un periodismo participativo que permita la colaboración activa de sus usuarios en todo el proceso informativo aún no es un posible, y de esto se puede dar cuenta en declaraciones como la siguiente: "No es que los usuarios intervengan de manera directa, pero con sus comentarios nos dejan ver qué es lo que les interesa" (Coordinadora editorial, comunicación personal n. ${ }^{\circ}$ 6, febrero del 2016), o cuando otra periodista señala: “Aquí no hacemos periodismo 
participativo, pero creo que deberíamos hacerlo" (Directora editorial, comunicación personal n. ${ }^{\circ} 8$, febrero del 2016).

Todos los periodistas consultados afirman que en su cibermedio solo aceptan la participación de los usuarios cuando se trata de sugerencias (antes de la publicación) o cuando reaccionan a los contenidos que produjeron (después de la publicación). Bajo esta perspectiva, siguiendo a Hermida, a los lectores se les confiere el papel de "receptores activos" (como se citó en Holton, 2013, p. 27), es decir, su participación es limitada y controlada.

La mayor interacción con los usuarios la tienen a través de las redes sociodigitales, en Facebook y Twitter, sobre todo, y del correo electrónico, ya sea al del cibermedio o a la cuenta de cada miembro del staff en particular. En estos casos, el grado de interacción es distinto entre cibermedios, algunos están más dispuestos a acortar la "distancia editorial" que otros, pero esto tiene que ver más con una decisión editorial del medio que por iniciativa de los propios periodistas.

Una parte muy importante de su adaptación a la interactividad tiene que ver con la apertura y promoción de espacios en sus sitios web como foros, chats y buzones de sugerencias, en los que se promueve la participación de los usuarios, y a través de ellos se busca crear una comunidad. Los periodistas destacan estas herramientas sobre otro tipo de contenidos por su capacidad para atraer lectores. Los cuatro cibermedios analizados cuentan, al menos, con alguno de estos productos.

En los foros y chats, a diferencia de otros espacios, la participación de la gente se incrementa, como afirman algunos periodistas:

Al día nos llegan como quince preguntas a través del foro. Los foros son algo muy especial, es un canal en donde el usuario puede hacer una pregunta a un experto, sobre todo. Ahí el usuario decide si le manda la pregunta a la comunidad o solo al experto. Y lo que hacemos editorialmente nosotros es que como a los doctores que están con nosotros no les pagamos, solo les ofrecemos el espacio de exhibición, retomamos todas las preguntas, las clasificamos y se las enviamos a los expertos. Si vemos que algunas de estas preguntas ya las hemos respondido, curamos una nota con la información que ya tenemos y la mandamos. Pero siempre respondemos para que al final del día se sientan acompañados y no digan que ellos se tomaron la molestia de escribirnos y nosotros no respondemos. (Editora, comunicación personal n. ${ }^{\circ}$, enero del 2016)

Nosotros tenemos un chat que es muy exitoso. Le pedimos a la gente que nos mande sus preguntas y en tiempo real un médico que invitamos a nuestra redacción les responde durante una hora. De ese ejercicio hacemos una versión escrita y hacemos un video. Aquí la gente es muy participativa. (Directora editorial, comunicación personal $n .^{\circ} 8$, febrero del 2016) 
Lo que ocurre en los foros y chats es un fenómeno muy particular. De acuerdo con los entrevistados, la gente ve en estos espacios una oportunidad para tratar de disipar todas sus dudas en materia de salud. A través de estas herramientas, los usuarios expresan todas las preguntas que por alguna razón no se atreven a hacer a un profesional de la salud o que buscan solucionar de una manera sencilla sin tener que asistir a una consulta médica.

Esta situación da atisbos de un problema más profundo que, aunque no es materia de esta investigación, se puede señalar: a través de estos espacios los usuarios se animan a preguntar sobre temas que afectan directamente su salud en diversos grados, aprovechando la virtualidad de la experiencia de una charla en la web con expertos o con mediadores, lo cual les acarrea a los periodistas algunas dificultades, como la que se indica a continuación:

Nuestro chat es la sección más exitosa del sitio, pero representa una responsabilidad muy grande, porque el lector le pregunta a la computadora como si estuviera en un consultorio frente a un médico. Incluso algunas de sus preguntas son sobre casos muy graves y a veces hasta me dan ganas de ponerles: "Qué hace escribiendo aquí, no espere más y vaya con urgencia con un doctor". Pero lo que hacemos, una vez que leemos todas las preguntas, es dirigirlas siempre a un especialista para que los lectores tengan una respuesta adecuada, que en verdad les ayude, y les damos información de algunos médicos o asociaciones que les pueden ayudar. Es muy común que los lectores entren al chat para pedir información para automedicarse, buscan saltarse la visita al doctor. Pero nosotros siempre en todas las respuestas que damos les dejamos muy claro que deben acudir a un médico. (Editora, comunicación personal n. ${ }^{\circ}$ 1, diciembre del 2015)

\section{Adaptación a la hipertextualidad}

En el ciberperiodismo en salud, la hipertextualidad es importante, porque a través de esta característica los periodistas dotan de contexto a sus contenidos, les da la posibilidad de ofrecer un mayor trasfondo en los temas que publican y de acercar a los usuarios con las fuentes originales, lo que concede mayor credibilidad a los contenidos. Sin embargo, su uso es muy limitado. Al respecto, algunos de los periodistas consultados expresan:

Los usamos básicamente para señalar alguna fuente, como algún journal o una investigación, y lo hacemos para que la gente tenga la certeza de que la información proviene de un experto. Por ejemplo, hemos publicado notas que dicen que si usas tacones de diez centímetros te vas dañar las pantorrillas y la gente se queja diciendo que no es posible que digamos eso, pero es real y para eso les ponemos links que los llevan a los estudios en donde sacamos el dato. El objetivo de esto es que cuando tú le des clic al hipervínculo veas que hay un estudio que sustenta lo que estamos diciendo, y aunque sea un tema tan trivial sepas que es real y que no estamos inventando. (Editora, comunicación personal n. ${ }^{\circ}$ 4, enero del 2016) 
Los links nos ayudan para mandar a los lectores a la página de alguna institución o un artículo científico, para que vean de dónde sacamos la información y tengan la posibilidad de obtener más datos. Pero por lo regular, eso lo hacemos en trabajos especiales, como reportajes, porque en la nota diaria no, porque la tenemos que subir lo antes posible. (Reportero, comunicación personal n. ${ }^{\circ} 3$, enero del 2016)

Pero estos enlaces no solo llevan a los usuarios al contenido externo, es decir, hacia otros sitios web, sino que le ofrecen al lector la posibilidad de reforzar esa información que leen con datos de otras de sus notas o servicios ciberdocumentales, como glosarios, directorios o guías, entre otros:

$\mathrm{Si}$, por ejemplo, una persona entra a una nota en donde mencionamos la palabra várices y quiere saber más del tema puede dar clic en el hipervínculo y la llevará a nuestro glosario en donde le informa qué es, las causas, sus características y los factores de riesgo. Es una forma de ampliar la información y de saber que tienes más alternativas acerca de un tema. Este glosario está hecho por médicos que trabajaron con nosotros, y nuestro equipo solo le dio una pulida para que se adaptara a nuestro estilo y algunos términos muy técnicos se entendieran lo mejor posible. (Editora, comunicación personal n. ${ }^{\circ}$, enero del 2016)

Al dar un clic en una palabra sombreada, lleva al lector a otra nota o a una explicación concreta al tema o al término. Porque ese también es uno de los fines de los sitios de salud, explicarles a los lectores las cosas que no entiende sobre sus enfermedades. (Editora, comunicación personal n. ${ }^{\circ} 1$, diciembre del 2015)

Aunado a esto, otro de los usos que los periodistas entrevistados les dan a los enlaces que llevan al lector al contenido de su cibermedio es para evitar que el usuario abandone su sitio web, para mantenerlo enganchado a su contenido el mayor tiempo posible, lo cual aumenta el tráfico en su sitio y les ofrece ventajas comerciales:

Nos dimos cuenta que el hipervínculo genera mucho rebote, es decir, el tiempo que dura un usuario dentro del sitio y lo podemos medir con Google Analytics. Regularmente se ponen dos hipervínculos, uno que te lleva a la fuente original y el segundo relacionado con el tópico que te lleva al glosario o a una nota relacionada. (Coeditora web, comunicación personal n. ${ }^{2}$, diciembre del 2015)

\section{Adaptación a la multimedialidad}

La multimedialidad es quizá la característica a la que se han adaptado con mayor facilidad los periodistas de salud. Incluso todos manifiestan una actitud positiva hacia la construcción de contenidos en diferentes formatos, ya que consideran que esto les permite ofrecer a los usuarios mejores trabajos periodísticos. Aunque la tendencia general es ofrecer contenidos yuxtapuestos, más que integrados. Sobre esto tres periodistas opinan lo siguiente: 
Antes pensábamos que en salud la imagen no era tan importante, considerábamos que lo único importante era tener tus fuentes, pero ahora contar con una imagen o un video de apoyo ayuda muchísimo, incluso se vuelve más ilustrativo, por ejemplo, cuando presentamos algún procedimiento médico, un ejercicio o unas posturas de yoga los lectores lo entienden mejor, porque no es lo mismo que solo te lo describan en un texto a que lo veas. Las infografías son una forma muy clara, sencilla y atractiva de presentar la información. Al igual que las fotografías son un gran apoyo. Lo importante es saber ocupar y combinar todas estas herramientas para brindar mejores contenidos. (Editora, comunicación personal n. ${ }^{\circ} 4$, enero del 2016)

Lo visual tiene un peso muy importante en nuestro trabajo, porque nos hemos dado cuenta que los videos, las fotogalerías y las infografías son muy populares. Sobre todo, los videos, por eso mis jefes me piden que todos los días tenemos que publicar al menos un video, ya sea que lo encontremos en Internet o que lo generemos nosotros. A las infografías también les damos mucho peso, pues una infografía puede explicarte un tema de manera muy sencilla, pero además se comparten mucho y eso nos importa. (Editora, comunicación personal n. ${ }^{\circ}$ 1, diciembre del 2015)

Una de las cuestiones a la que han tenido que adaptarse ha sido que ahora planean sus coberturas en función del tipo de formato que quieren presentar. Lo cual, explican, depende mucho del tema: "La misma información te lo dice, tú te das cuenta si un tema se puede desplegar mejor en texto o si tiene una vertiente más visual que te permita desarrollar una infografía o hacer un video" (Coordinadora editorial, comunicación personal n. ${ }^{\circ}$ 6, febrero del 2016). Aunque regularmente esto lo deciden en las juntas editoriales, en las que durante la planeación de las agendas informativas se discuten los formatos más adecuados para cada contenido:

Si es una nota, por ejemplo, sobre cáncer de mama, y hacemos una fotogalería, no servirá de nada, será muy banal, porque no te va a aportar nada, porque ¿qué puedes poner? Pero si se trata de posturas de yoga o alguna rutina de ejercicios, el tema se convierte en algo más visual y aquí puedes hacer una fotogalería o una videonota, porque te permite ver los movimientos o seguir el paso a paso para que lo puedas hacer tú. Depende mucho de la temática y la claridad para el usuario, qué formato le va a aportar más. Cuando yo mando la agenda editorial me imagino cada contenido y les sugiero que cierto tema puede ir mejor con fotos o video. Lo que hago es pensar como el usuario, respondiendo un poco al uso que le pueda dar la gente a ese contenido. (Editora, comunicación personal n. ${ }^{\circ}$, enero del 2016)

De acuerdo con los periodistas entrevistados, ninguno se ve forzado a tomar sus propias fotografías o videos, salvo que así lo consideren necesario, ya que cada uno de sus medios cuenta con un área que se encarga de esto, con la que se coordina para realizar algún proyecto, y además tienen a su disposición bancos de imágenes en línea de los cuales echar mano. 


\section{Adaptación a la inmediatez}

El fenómeno de la inmediatez marca el ritmo de las rutinas de los profesionales consultados, lo cual se manifiesta en la producción diaria de sus contenidos y en los cambios de la portada de sus sitios web.

Según relatan, el ciberperiodismo en salud no es ajeno a esta tendencia de subir a la red pequeñas dosis de información cuando ocurre un breaking news para ganar la primicia y después complementarla o modificarla constantemente hasta obtener una nota terminada, aunque esto implique utilizar información no corroborada en el proceso. "Los sitios de salud no estamos exentos de eso, también estamos expuestos a cometer errores por la velocidad y por la necesidad de generar hits o ganar muchas visitas" (reportero, comunicación personal n. ${ }^{\circ}$, enero del 2016).

Una periodista señala que cuando se trata de una noticia de última hora tiene que preparar un texto en menos de diez minutos para subirlo a su sitio: "En ese tiempo tienes que tener tres párrafos de información con fotos arriba. Ya después tendrás tiempo de seguir trabajando la nota mientras cae más información. Lo más importante es subirla cuanto antes" (redactora, comunicación personal n. ${ }^{\circ} 10$, marzo del 2016).

Los periodistas entrevistados mencionaron que suben entre diez y veinte contenidos todos los días, y el home de sus sitios lo cambian entre tres y cinco veces al día dependiendo del flujo informativo. Generalmente el primer cambio lo hacen entre las nueve y las diez la mañana; el segundo, entre la una y las tres de la tarde. Al respecto una coeditora expresa: "Hemos notado que, en ese lapso, cuando la gente sale a comer hay un pico de lectura muy interesante" (coeditora web, comunicación personal n. 7 , febrero del 2016). El tercero cambio se da entre las seis de la tarde y las nueve de la noche. La idea es mostrar un flujo constante, que cada vez que un usuario entre al sitio vea un cambio, para dar la sensación de movimiento.

\section{DISCUSIÓN Y CONCLUSIONES}

\section{La adaptación del periodismo en salud al entorno digital es lenta y dispar}

Pese a que, como se puede constatar, los periodistas en salud y los medios en México son cada vez más conscientes de la importancia de la interactividad, hipertextualidad, multimedialidad e inmediatez en la construcción de contenidos informativos, no han podido adaptarse a ellas del todo, ni aprovecharlas, en la medida de sus posibilidades, para enriquecer los productos que ofrecen a sus usuarios, debido a diversos factores relacionados, sobre todo, con la falta de personal para cumplir con todas las funciones requeridas en la redacción del cibermedio y la carencia de habilidades para el trabajo en el medio digital. 
Los periodistas en salud, al igual que un buen número de profesiones que se desenvuelven en el medio digital, se encuentran en una encrucijada entre la tradición y la innovación. El periodista de salud en Internet es un perfil en construcción.

Por un lado, las rutinas tradicionales arraigadas que han guiado el ejercicio profesional de la mayoría de los periodistas consultados siguen reflejándose en su actividad diaria. Por otra parte, se reconoce la necesidad de un cambio, más de forma que de fondo, basado en la adopción de rápidos ajustes, sobre todo tecnológicos, en los procesos de elaboración de contenidos, lo que les genera incertidumbre y desconcierto.

Esta situación ha propiciado una lenta adaptación al entorno digital, porque ante la falta de conocimiento del nuevo medio y de sus potencialidades, y al mismo tiempo, la necesidad de una rápida inmersión en él, se trabaja tras el velo de la experimentación constante que los obliga a dar pasos en falso y retroceder el andar para reorganizar su plan de acción. Por eso muchas veces optan por sostenerse del pilar de la rutina para sacar adelante su trabajo.

Con esto no se quiere decir que los periodistas en salud consultados no están buscando la forma de aprovechar las características del ciberperiodismo para mejorar sus prácticas y sus productos. Sobre todo, en lo que tiene que ver con la interactividad, se observan diversos esfuerzos para fomentar la participación de los usuarios y mejorar su experiencia a través de recursos presentes en los contenidos. Pero sí es evidente que estos esfuerzos no se aplican con la misma intensidad en la hipertextualidad, multimedialidad e inmediatez, que presentan un nivel muy pobre de innovación.

En cuanto a la búsqueda de información, para todos los periodistas entrevistados internet representa la principal vía para acopiar y seleccionar la información que nutre sus contenidos.

La primera acción que realizan todos los profesionales consultados, y la cual se repite a lo largo de su jornada de trabajo, es navegar en la red para buscar en los sitios web de otros medios, sobre todo, para "saber qué traen" y que no se les escape ningún tema, siguiendo la creencia arraigada de que se debe coincidir con lo que la competencia está reportando, para después revisar los sitios de instituciones de salud, universidades, revistas científicas especializadas y sociedades de pacientes.

Y luego de esta primera búsqueda, consultan su correo electrónico y sus redes sociodigitales con la intención de revisar si alguien les compartió algún comunicado de prensa o les envió alguna invitación para cubrir un evento o realizar una entrevista, de los cuales pueden generar algún contenido.

Asimismo, las redes sociodigitales de los profesionales de la salud, así como los sitios web de hospitales, consultorios particulares, institutos de investigación y universidades se han convertido en herramientas indispensables para encontrar posibles 
fuentes de información y ponerse en contacto con ellas desde sus computadoras, ya que, como afirma Barrera Páez, "en los últimos años la eclosión de Internet ha hecho que la forma de acceder a la información cambie por completo" (2016, p. 15).

La reconfiguración de la estructura organizativa de los cibermedios, que tiende a la reducción de los equipos de trabajo (independientemente del tipo de cibermedio) y a la multiplicación de las tareas periodísticas (como consecuencia de este recorte de personal), ha propiciado la sustitución del trabajo en la calle, por el "cibertrabajo", el que se realiza sin dejar la sala de redacción, para poder incorporarse a una rutina demandante y agotadora.

Aunque esto es más evidente en los cibermedios nativos como sumedico.com, salud180. com y sinembargo.com, en reforma.com, que es un cibermedio que procede de un medio tradicional, también ocurre, ya que la periodista responsable de la edición digital de la sección de salud rara vez realiza coberturas fuera de las instalaciones del diario; el trabajo de investigación en las calles lo hacen los reporteros, quienes proveen de información a los dos soportes (impreso y digital), pero cuya prioridad está en la versión en papel.

Esta situación ha provocado la disminución drástica de la información original como resultado de un trabajo riguroso de investigación, que requiere tiempo, reflexión y dinero para su elaboración, por la sobreabundancia de notas que resultan de un proceso de curaduría que produce contenidos estandarizados y descontextualizados. Y que, al mismo tiempo, dicho fenómeno conduce a la precarización del ciberperiodismo de salud y al debilitamiento del papel de sus periodistas como mediadores entre las fuentes de información y los usuarios y como generadores de contenidos que ayuden a tomar decisiones informadas.

La adaptación del periodismo de salud a las características del ciberperiodismo no se vislumbra en el corto plazo, pues, como afirma Fidler, de acuerdo con "el principio de la adopción retrasada" (2000, p. 376), su implementación y adopción generalizada llevará mucho más tiempo de lo que se piensa, así como ha ocurrido con las otras formas de periodismo, por tratarse de un fenómeno complejo y en constante evolución. Este proceso se llevará, al menos, una generación de periodistas, la de quienes actualmente están al frente de los cibermedios construyendo contenidos con los conocimientos, habilidades y recursos técnicos de que disponen.

Mientras tanto se tendrán que impulsar diversos cambios, empezando por la capacitación continua de los periodistas en activo, la propuesta y desarrollo de nuevos modelos de negocio para los cibermedios, el fortalecimiento de las salas de redacción a través de la incorporación de un mayor número de profesionales de la información y la incorporación en los planes de estudio de las carreras de comunicación y periodismo de asignaturas con enfoque hacia la producción periodística digital y la especialización en salud y ciencia. 


\section{Hay poca capacitación en el periodismo en salud}

Para los entrevistados la capacitación continua es muy importante, pero más que en el periodismo en salud lo es en la producción periodística digital, en la gestión de redes sociodigitales y en marketing.

Esto se debe a que, con la incorporación de las nuevas funciones y perfiles profesionales en las redacciones, los medios están exigiendo a los periodistas una serie de capacidades básicas. De acuerdo con el estudio Superpowers: The digital skills newsrooms need, publicado en el 2016 por el Tow-Knight Center for Entrepreneurial Digital Journalism de Estados Unidos (como se citó en Asociación de la Prensa de Madrid, 2016), estas se dividen en capacidades fundamentales u originarias (fundational skills) y capacidades adaptativas (adaptative skills). Entre las primeras están las que tradicionalmente favorecen la búsqueda, la elaboración y la edición de noticias, mientras que las segundas están directamente relacionadas con las características del medio digital.

A partir del análisis de los datos obtenidos se concluye que las capacidades fundamentales ya no son suficientes para realizar el trabajo en los cibermedios, por lo que ahora al momento de seleccionar a su personal las empresas periodísticas buscan profesionales que cuenten con capacidades adaptativas; entre las cinco más solicitadas están: programación de páginas web, desarrollo de audiencias y análisis de datos y métricas, narrativa audiovisual y edición de fotografía y video, diseño digital para la web y dispositivos móviles y administración y generación de contenidos para redes sociodigitales.

Si se considera que en las redacciones de los cibermedios analizados todos los periodistas, salvo uno, provienen del periodismo tradicional, es posible afirmar que su fortaleza está en las técnicas clásicas de la profesión, por eso su prioridad está en aprender las capacidades adaptativas que les permitan enfrentar los retos relacionados con el nuevo medio. $Y$ dejan en segundo plano los conocimientos que tienen que ver con la especialización periodística en salud.

Porque, además, buena parte de ellos realizan varias funciones. De esta manera, es muy común que un solo periodista busque información y construya, edite y publique los contenidos en diferentes formatos y para diferentes soportes, pero también administre y comparta información en redes sociodigitales y esté pendiente de las estadísticas relacionadas con el número de visitas y el número de veces que se comparten los contenidos.

Es decir, buscan capacitarse en actividades que les permitan adaptar sus perfiles profesionales a las necesidades del mercado laboral, y esto implica para muchos de ellos acomodarse en un medio, independientemente de la especialización periodística. Porque, además, se considera que teniendo las habilidades periodísticas básicas es posible desarrollarse en cualquier sección. Y un claro ejemplo de esto son los periodistas entrevistados, ya que todos han trabajado en otras secciones, además, o a la par, de la de salud. 
Los periodistas con más experiencia en la fuente de salud son los que más se han capacitado en este campo; en cambio, los que menos tiempo tienen son los más interesados en desarrollar primero sus capacidades adaptativas, ya que solo están de paso, y su interés está en migrar a otra sección en cuanto tengan la oportunidad.

\section{REFERENCIAS}

Asociación de la Prensa de Madrid (2016). Informe anual de la profesión periodística 2016. Madrid: Asociación de la Prensa de Madrid. Recuperado de http:// www.apmadrid.es/wp-content/uploads/2017/10/Informe_anual_profesion_ APM_2016_baja_7mg.pdf

Barrera Páez, L. (2016). El periodismo especializado en salud: una reseña histórica. Revista Española de Comunicación en Salud, 0, 15-22. Recuperado de https://e-revistas. uc3m.es/index.php/RECS/article/view/3118/1869

ComScore (2013). 24 Percent of Mexican Internet users visited health sites in February 2013.

Recuperadodehttp://www.comscore.com/Insights/Press-Releases/2013/3/24Percent-of-Mexican-Internet-Users-Visited-Health-Sites-in-February-2013

Díaz Noci, J. (2006). La interactividad y el periodismo online: una aproximación teórica al estado de la cuestión. Diálogos Possíveis: revista da Faculdade Social da Bahia, 9-28. Recuperado de http://fba.unlp.edu.ar/lenguajemm/?wpfb_dl=61

Fidler, R. (2000). Mediamorfosis: comprender los nuevos medios. Buenos Aires: Editorial Granica.

Holton, A. (2013). A Journalistic Chasm? Normative perceptions and participatory and gatekeeping roles of organizational and entrepreneurial health journalists (Tesis de Doctorado). Universidad de Texas. Recuperado de https://repositories.lib. utexas.edu/bitstream/handle/2152/22987/HOLTON-DISSERTATION-2013. pdf?sequence $=1 \&$ isAllowed $=y$

Levy, D., Newman, N., Fletcher, R. y Nielsen, R. (2016). Reuters Institute Digital News Report 2016. Oxford: Reuters Institute for the Study of Journalism / University of Oxford. Recuperado de http://reutersinstitute.politics.ox.ac.uk/sites/default/ files/research/files/Digital\%2520News\%2520Report\%25202016.pdf?utm_ medium=referral\&utm_source=digitalnewsreport.org

Roqué, P. (2007). Portales de salud. "Intervención en salud en la red". UOC Papers. Revista sobre la sociedad del conocimiento, 4, 42-43. Recuperado de http://www. pewinternet.org/files/old-media/Files/Reports/2006/PIP_Online_Health_2006. pdf.pdf 
Salaverría, R. (Coord.) (2016). Ciberperiodismo en Iberoamérica. Barcelona: Ariel.

Shah, A. (2011). HealthjournalismtakeawaysfromtheAnnualStateoftheMediaReport.TheCenter of Health Journalism. Recuperado de https://www.centerforhealthjournalism. org/blogs/health-journalism-takeaways-annual-state-media-report

Shoemaker, P. y Reese, S. (1996). Mediating the message: Theories of influences on mass media content. Nueva York: Longman. 
